From the Risk and Prevention Conference

\title{
Improving Compliance With Hand Hygiene in Hospitals
}

\author{
Didier Pittet, MD, MS
}

\begin{abstract}
Hand hygiene prevents cross-infection in hospitals, but compliance with recommended instructions often is poor among healthcare workers. Although some previous interventions to improve compliance have been successful, none has achieved lasting improvement. This article reviews reported barriers to appropriate hand hygiene and factors associated with poor compliance.

Easy access to hand hygiene in a timely fashion and the availability of skin-care lotion both appear to be necessary prerequisites for appropriate hand-hygiene behavior. In particular, in high-demand situations, hand rub with an alcohol-based solution appears to be the only alternative that allows a decent compliance.

The hand-hygiene compliance level does not rely on individual factors alone, and the same can be said for its promotion. Because of the complexity of the process of change, it is not surprising that solo interventions often fail, and multimodal, multidisciplinary strategies are necessary. A framework that includes parameters to be considered for hand-hygiene promotion is proposed, based on epidemiologically driven evidence and review of the current knowledge. Strategies for promotion in hospitals should include reasons for noncompliance with recommendations at individual, group, and institutional levels. Potential tools for change should address each of these elements and consider their interactivity (Infect Control Hosp Epidemiol 2000;21:381-386).
\end{abstract}

Hand hygiene is considered the most important measure to reduce the transmission of nosocomial pathogens in healthcare settings. As recently reviewed by Larson in a comprehensive article, ${ }^{1}$ seven quasi-experimental hospitalbased studies of the impact of hand hygiene on the risk of nosocomial infection have been published between 1977 and $1995 .^{2-8}$ Despite study limitations, most reports showed a temporal relation between improved hand-hygiene practices and reduced infection rates. Similarly, the beneficial effects of hand-hygiene promotion on the risk of crosstransmission have been reported in surveys conducted in schools or day-care centers, ${ }^{9-12}$ as well as in a community setting. ${ }^{13-15}$

Despite such evidence, studies in the literature have repeatedly documented that the importance of this simple procedure is not sufficiently recognized by healthcare workers (HCWs), ${ }^{16}$ and compliance with recommended hand-hygiene practices is unacceptably low. ${ }^{8,16-21}$

This article reviews factors that may explain the lack of adherence by HCWs to hand-hygiene procedures and suggests strategies for promotion in hospitals.

\section{DEFINITIONS}

Three groups of microorganisms may be distinguished on the skin: organisms that reside on the skin (resident flora), those that happen to be there as contaminants (transient flora), and pathogens responsible for infections, such as paronychia or panaritium digiti (infectious flora). Unless introduced into body tissue by trauma or in conjunction together with foreign bodies, such as intravenous catheters, the pathogenic potential of the resident flora is usually regarded as low. ${ }^{22}$ In contrast to natural resident flora, transient flora are responsible for most nosocomially acquired infections resulting from cross-transmission, but are easily removed by hand cleansing.

Hand hygiene (not including surgical hand scrub) defines several actions designed to decrease hand colonization with transient flora and can be achieved either through hand washing or hand disinfection. Hand washing refers to the action of washing hands with an unmedicated detergent and water, or water alone, to remove dirt and loose transient flora to prevent cross-transmission. ${ }^{21,22}$ Hygienic hand wash refers to the same procedure when an

From the Infection Control Program, Department of Internal Medicine, University of Geneva Hospitals, Geneva, Switzerland.

Address reprint requests to Didier Pittet, $M D, M S$, Professor of Medicine, Director, Infection Control Program, Department of Internal Medicine, 24, rue Micheli-du-Crest, University of Geneva Hospitals, 1211 Geneva 14, Switzerland.

The author thanks members of the Infection Control Program at the University of Geneva Hospitals, who have been involved in research and institutional projects related to hand-hygiene compliance and promotion since 1993. The author is indebted to Rosemary Sudan for editorial assistance.

O0-RVC-035. Pittet D. Improving compliance with hand hygiene in hospitals. Infect Control Hosp Epidemiol 2000;21:381-386. 
TABLE 1

Studies of Compliance With Hand Hygiene

\begin{tabular}{lcclc}
\hline Author & Reforence & Year & Setting & $\begin{array}{c}\text { Average } \\
\text { Compllance, \% }\end{array}$ \\
\hline Preston & 43 & 1981 & $\begin{array}{l}\text { Open ward } \\
\text { ICU }\end{array}$ & 16 \\
& & & 30 \\
Albert & 17 & 1981 & ICUs & 41 \\
& & & ICUs & 28 \\
Larson & 44 & 1983 & All wards & 45 \\
Donowitz & 36 & 1987 & PICU & 30 \\
Graham & 18 & 1990 & ICU & 32 \\
Dubbert & 24 & 1990 & ICU & 81 \\
Pettinger & 45 & 1991 & SICU & 51 \\
Larson & 46 & 1992 & NICU/others & 29 \\
Doebbeling & 8 & 1992 & ICUs & 40 \\
Zimakoff & 47 & 1995 & ICUs & 40 \\
Pittet & 20 & 1999 & All wards & 48 \\
& & & ICUs & 36
\end{tabular}

Abbreviations: ICU, intensive care unit; NICU, neonatal intensive care unit; PICU, pediatric intensive care unit; SICU, surgical intensive care unit.

antiseptic agent is added to the detergent. Hand disinfection refers to any action where an antiseptic solution is used to clean hands (either medicated soap or alcohol). Some experts may refer to the action of de-germing with detergent-based antiseptics or alcohol. ${ }^{1}$ Hygienic hand rub consists in rubbing hands with a small quantity $(2-3 \mathrm{~mL})$ of a highly effective and fast-acting antiseptic agent.

Because alcohols have excellent antimicrobial activity and the most rapid action of all antiseptics, they are the preferred agents for hygienic hand rub (also called waterless hand disinfection). Of particular importance is that alcohols dry very rapidly, allowing for fast hand disinfection without the need to return to the sink constantly, to wash hands with water and soap, to dry them, and to come back to the patient bedside to resume care. Because alcohol alone does not have any lasting effect, another compound with antiseptic activity is sometimes added to the hand-disinfection solution to obtain a prolonged effect. The main antiseptics recently were reviewed extensively by Rotter. ${ }^{22}$

\section{COMPLIANCE WITH HAND HYGIENE}

Compliance with hand-hygiene recommendations usually is below $50 \%$ (Table 1). Although opportunities for hand hygiene were not recorded in a standardized manner in these studies, it is still fair to say that compliance was almost universally low. As shown, it varied according to the hospital ward where the observation was conducted. In most surveys, compliance was observed more frequently in nurses than physicians.

\section{BARRIERS TO APPROPRIATE HAND HYGIENE}

Perceived barriers to appropriate hand hygiene have been reported by $\mathrm{HCWs}{ }^{20,23-28}$ These include reasons as
TABLE 2

Main Reasons for PoOr COMPlance With Hand Hygiene

\begin{tabular}{lcc}
\hline & $\begin{array}{c}\text { Self- } \\
\text { Report- } \\
\text { od }\end{array}$ & Observed \\
\hline 1. Skin irritation by hand-hygiene agents & $\mathrm{X}^{\star}$ & $\mathrm{X}$ \\
2. Inaccessible hand-hygiene supplies & $\mathrm{X}$ & $(\mathrm{X})^{\dagger}$ \\
3. Interference with HCW-patient relationship & $\mathrm{X}$ & ? \\
4. Patient needs take priority & $\mathrm{X}$ & ? \\
5. Wearing of gloves & $\mathrm{X}$ & $\mathrm{X}$ \\
6. Not thinking about it or forgetfulness & $\mathrm{X}$ & $(\mathrm{X})$ \\
7. Lack of knowledge of guidelines & $\mathrm{X}$ & $(\mathrm{X})$ \\
8. Lack of scientific information on effect of & & \\
hand hygiene on nosocomial infection rates & $\mathrm{X}$ & $(\mathrm{X})$ \\
9. Too busy or insufficient time for hand hygiene & $\mathrm{X}$ & $(\mathrm{X})$ \\
10. High work load ${ }^{\ddagger}$ or lack of appropriate staffing & $\mathrm{X}$ & $\mathrm{X}$ \\
11. Being a physician (rather than a nurse) & $\mathrm{X}$ & $\mathrm{X}$ \\
12. Male (rather than female) gender & $\mathrm{X}$ & $(\mathrm{X})$ \\
13. Working in high-risk areas (ie, ICUs) & $\mathrm{X}$ & $\mathrm{X}$ \\
14. Activities with high risk for cross-transmission & & $\mathrm{X}$ \\
15. Working on weekdays (vs weekends) & & $\mathrm{X}$ \\
16. Lack of hand-hygiene promotion at individual \\
or institutional level & & \\
17. Lack of role model for hand hygiene & $\mathrm{X}$ ) & $(\mathrm{X})$ \\
18. Lack of institutional priority for hand hygiene & $\mathrm{X}$ & $(\mathrm{X})$ \\
19. Lack of administrative sanction of noncompliers & & \\
or rewarding of compliers & $\mathrm{X}$ & \\
20. Lack of institutional safety climate & $(\mathrm{X})$ & \\
\hline
\end{tabular}

Abbreviations: $\mathrm{HCW}$, healthcare worker; ICU, intensive care unit.

* $\mathrm{X}$ refers to reasons for poor compliance with hand hygiene that have been frequently selfreported or have been observed in observational or analytical studies.

$t(X)$ refers to reasons for poor compliance with hand hygiene that have been self-reported on occasion in the "Discussion" section of a paper, but have not been confirmed in observational or analytical studies.

₹As assessed by a high number of opportunities for hand hygiene per hour of patient care

different as the following: hand hygiene agents cause skin irritation and dryness; patient needs take priority over hand hygiene; sinks are inconveniently located or not available; glove use dispenses with the need for additional hand hygiene; $\mathrm{HCW}$ has inadequate knowledge of guidelines or protocols for hand hygiene; there is lack of role models (superiors or peers); there is lack of recognition of the risk of cross-transmission of microbial pathogens; or simply forgetfulness.

Some of these perceived barriers have been assessed or even quantified in observational studies. ${ }^{16,23-29}$ Table 2 lists 20 reasons for poor compliance. Some are discussed below.

Skin irritation by hand-hygiene agents constitutes an important barrier to appropriate compliance..$^{30}$ The superficial skin layers contain water to keep the skin soft and pliable, and lipids to prevent dehydration of the corneocytes. Hand cleansing can increase skin $\mathrm{pH}$, reduce lipid content, increase transepidermal water loss, and even increase microbial shedding. Soaps and detergents are damaging substances when applied to skin on a regular 
basis. Importantly, however, HCWs need to be informed better about the possible effects of hand-hygiene agents. Lack of knowledge and education on this topic is a key barrier to motivation. In particular, it is extremely important to recall that alcohol-based formulations for hand disinfection (whether isopropyl, ethyl, or n-propanol, in 60\%-90\% $\mathrm{vol} / \mathrm{vol}$ ) are less irritating to skin than any antiseptic or nonantiseptic detergents; alcohols, with the addition of appropriate emollients, are at least as tolerable and as efficacious as detergents; emollients may even be protective against cross-infection by keeping the resident skin flora intact; and hand lotions help to protect skin and may reduce microbial shedding. These issues recently were reviewed in detail by Elaine Larson. ${ }^{1}$

The need for ready access to hand-hygiene supplies, whether sink, soap, medicated detergent, or waterless alcohol-based hand-rub solution, is self-evident. Asking busy HCWs to walk away from the patient bed to reach a wash basin or to get a hand antisepsis solution invites noncompliance with hand-hygiene recommendations. Engineering controls could facilitate compliance, but careful monitoring of hand-hygiene behavior should be conducted to exclude possible negative effects of newly introduced devices. ${ }^{31}$

Wearing of gloves might represent a barrier for compliance with hand hygiene. ${ }^{32}$ Noncompliance has been identified among glove users in at least two studies. ${ }^{19,33}$ It is important to recognize that hand hygiene is required whether or not gloves are used or changed. Failure to remove gloves after patient contact or between dirty and clean body-site care on the same patient has to be regarded as noncompliance with hand-hygiene recommendations. ${ }^{20}$ Furthermore, Doebbeling and colleagues ${ }^{34}$ concluded from their experiment, involving conditions close to clinical practice, that it may not be prudent to wash and reuse gloves between patient contact and that hand washing or disinfection should be strongly encouraged after glove removal. The authors recovered test organisms from $4 \%$ to $100 \%$ of the gloves and observed bacterial counts between 0 and $4.7 \log _{10}$ on the hands after glove removal.

Lack of knowledge of guidelines for hand hygiene, lack of recognition of hand-hygiene opportunities during patient care, and lack of awareness of the risk of microbial cross-transmission constitute barriers to hand-hygiene compliance. Another finding was that some HCWs believed that they washed their hands when necessary, even when observations indicated that they did not. ${ }^{24}$ Finally, some HCWs argued that the lack of scientific information of the definitive impact of improved hand hygiene on nosocomial infections rates decreases their motivation to comply with recommendations.

All of the above-described parameters need to be addressed in HCW education.

\section{RISK FACTORS FOR NONCOMPLIANCE}

Risk factors for noncompliance with hand hygiene have been determined objectively in several observational studies or interventions to improve compliance. ${ }^{16,23-29}$
Among them, being a physician or a nursing assistant rather than a nurse was commonly associated with reduced compliance.

In the largest survey conducted so far, ${ }^{20}$ we also identified predictors of noncompliance with hand hygiene during routine patient care using a hospitalwide survey. Predictor variables included professional category, hospital ward, time of day or week, and type and intensity of patient care (defined as the number of opportunities for hand hygiene per hour of patient care). In 2,834 observed opportunities for hand hygiene, average compliance was $48 \%$. In multivariate analysis, noncompliance was lowest among nurses, compared with other HCWs, and on weekends (odds ratio $[\mathrm{OR}], 0.6 ; 95 \%$ confidence interval $\left[\mathrm{CI}_{95}\right], 0.4-$ 0.8 ); it was higher in intensive care units (compared with internal medicine: $\left.\mathrm{OR}, 2.0 ; \mathrm{CI}_{95}, 1.3-3.1\right)$; during procedures that carry a high risk of bacterial contamination (OR, 1.8; $\left.\mathrm{CI}_{95}, 1.4-2.4\right)$; and when intensity of patient care was high (compared with $0-20$ opportunities; $21-40$ opportunities: $\mathrm{OR}, 1.3 ; \mathrm{CI}_{95}, 1.0-1.7 ; 41-60$ opportunities: $\mathrm{OR}, 2.1 ; \mathrm{CI}_{95}, 1.5-$ 2.9 ; >60 opportunities: $\left.\mathrm{OR}, 2.1 ; \mathrm{Cl}_{95}, 1.3-3.5\right)$. This study confirmed modest levels of compliance with hand hygiene in a teaching institution and showed that compliance varied by hospital ward and by type of $\mathrm{HCW}$, thus suggesting that targeted educational programs might be useful. Most importantly, high demand for hand hygiene (ie, overwork) was associated with low compliance. The results of this study also suggested that full compliance with current guidelines may be unrealistic ${ }^{20,29,35}$ and that facilitated access to hand hygiene could help improve compliance.

\section{IMPROVING COMPLIANCE WITH HAND HYGIENE}

Educational programs, distribution of information leaflets, workshops and lectures, automated dispensers, and performance feedback on hand-hygiene compliance rates have been associated with, at best, transient improvement in hand-hygiene rates. ${ }^{2,16,18,24,36,37}$

No single intervention has consistently been shown to sustain improved compliance with respect to HCWs' infection control practices. ${ }^{27}$ The most effective strategy documented so far has been routine observation and feedback. $^{18,24,37}$ In 1998, Kretzer and Larson ${ }^{28}$ revisited the major behavioral theories and their applications with regard to the health professions in an attempt to understand better how one might plan more successful interventions. They proposed a hypothetical framework to enhance hand-hygiene practices and stressed the importance of considering the complexity of individual and institutional factors when designing behavioral interventions.

Behavioral theories and secondary intervention have primarily targeted individuals. We agree with Kretzer and Larson $^{28}$ that this is insufficient to effect sustained change $\mathrm{e}^{28,38,39}$ and that interventions aimed at improving compliance with hand hygiene must consider the various levels of behavior interaction. ${ }^{28,29,40}$ Thus, the interdependence of individual factors, environmental constraints, and the institutional climate all need to be taken into account in the strategic 
TABLE 3

Hand Hygiene: Distrubution of Factors Associated Wrth NONCOMPLIANCE

Individual level
Lack of education or experience
Being a physician
Male gender
Lack of knowledge of guidelines
Being a refractory noncomplier
Group level
Lack of education or lack of performance feedback
Working in critical care (high work load)
Downsizing or understaffing
Lack of encouragement or role model from key staffs
Institutional level
Lack of written guidelines
Lack of suitable hand-hygiene agents
Lack of skin-care promotion or agent
Lack of hand-hygiene facilities
Lack of culture or tradition of compliance
Lack of administrative leadership, sanction, rewards, or support

planning and development of hand-hygiene promotion campaigns. ${ }^{28,29,39}$ Parameters associated with noncompliance with hand-hygiene recommendations are related not only to the individual $\mathrm{HCW}$ but also to the group he or she is working in and, by extension, to the institution to which the latter belongs (Table 3). Interventions to promote hand hygiene in hospitals should consider variables at all of these levels.

The dynamics of behavioral change are complex. It involves a combination of education, motivation, and system change. The factors necessary for a change include the dissatisfaction with the current situation, the perception of alternatives, and the recognition, both at the individual and institutional level, of one's ability and potential to change. While the latter implies education and motivation, the former two necessitate primarily a system change.

Reported reasons for noncompliance include the lack of hand-hygiene promotion, active participation at the individual and institutional level, the frequent lack of a role model by senior staff, the lack of institutional priority for hand hygiene, the lack of administrative sanctions for noncompliers or the rewarding of compliers, and the lack of an institutional safety climate. The latter would involve topmanagement commitment, visible safety programs, a low level of work stress, a tolerant and supportive attitude toward reported problems, and belief in the efficacy of preventive strategies. ${ }^{28,29,39,41}$

\section{TOOLS FOR CHANGE}

An improvement in infection control practices requires the following: questioning basic beliefs; continuous assessment of the group's (or individual's) stage of behavioral change; intervention(s) with an appropriate process of change; and supporting individual and group creativity. ${ }^{28}$ Because of the complexity of the process of change, it is not

\section{TABLE 4}

Parameters Associated With Successful Hand-Hygiene PROMOTION

Education
Routine observation and feedback
Engineering controls
Making hand hygiene possible, easy, and convenient
Making alcohol-based hand rub available (at least in high-demand
$\quad$ situations)
Patient education
Reminders in the workplace
Administrative sanctions and rewards
Change in hand-hygiene agent (but not in the winter)
Promote and facilitate healthcare worker hands' skin care
Obtain active participation at individual and institutional level
Maintain an institutional safety climate
Enhance individual and institutional self-efficacy
Avoid overcrowding, understaffing, and excessive workload

surprising that single interventions often fail. Thus, a multimodal, multidisciplinary strategy is necessary.

Table 4 proposes a framework that includes parameters to be considered for hand-hygiene promotion. Some of these are based on epidemiologically driven evidence, others on the authors' and other investigators' experiences and review of the current knowledge. Some of these parameters may be unnecessary in some circumstances, but may help in others. In particular, changing the handhygiene agent could be beneficial in institutions or hospital wards with a high work load and a high demand for hand hygiene when waterless hand rub is not available.,4,420,42 $\mathrm{A}$ change in the recommended hand-hygiene agent could however be deleterious if introduced during the winter, at a time of higher skin irritability.

As explained previously, several parameters that potentially could be associated with successful promotion of hand hygiene need, or would require, a system change (Table 4). Once again, hand-hygiene compliance does not rely on individual factors alone, and the same can be said for its promotion. Enhancing individual and institutional capabilities to organize and execute actions to reach the objective, obtaining active participation at both levels, and promoting an institutional safety climate represent major challenges that go well beyond the current perception of the infection control practitioner's common role. This, however, should not stop this effort. As a French proverb says, "Les petits ruisseaux font les grandes rivières" (great oaks from little acorns grow).

Easy access to hand hygiene in a timely fashion and the availability, free of charge, of skin-care lotion both appear to be necessary prerequisites for appropriate handhygiene behavior and are easier to obtain than major system change. In particular, in high-demand situations, such as in most critical-care units, in high-stress working conditions, and at times of overcrowding or understaffing, hand rub with an alcohol-based solution appears to be the only alternative that allows decent compliance. 
TABLE 5

HAND-HygIENE RESEARCH Issues

How can more definitive scientific evidence for the impact of improved compliance with hand hygiene on infection rates be generated?

How much hand washing is enough?

What percentage increase in hand hygiene does it take to achieve a predictable risk reduction in infection rates?

Should we encourage or discourage the use of gloves?

What are the key determinants of hand-hygiene behavior and promotion?

Should hand disinfection replace conventional hand washing?

What are the most suitable hand-hygiene agents? Should

hand-hygiene solutions include a long-lasting compound?

How can top-management support be obtained?

And last but not least (Table 4), strategies to improve compliance with hand-hygiene practices should be multimodal and multidisciplinary. It is important to note, however, that the proposed framework needs further research before implementation.

\section{AGENDA FOR RESEARCH}

Many questions remain unanswered, and this review may bring more questions than answers to infection control practitioners. Table 5 lists some of the key questions for infection control practitioners, laboratory research scientists, and behavioral epidemiologists regarding the practices of hand hygiene in the healthcare setting today.

The challenge of hand-hygiene promotion could be summarized in one single question, "How to change HCWs' behavior?" Tools for change are known but need to be tested. Some may prove to be irrelevant in the future; others have worked in some institutions and need to be tested in others. Behavioral epidemiology is a science, and research in behavior change is a research; funding agencies must be convinced that good research needs resources, and peer-review journal editorial boards and faculty chairpersons need to reconsider their views on this matter. Our job, as infection control professionals, is to provide outstanding research and practical solutions to improve our understanding and the impact of hand-hygiene promotion, to the ultimate benefit of the patient.

\section{REFERENCES}

1. Larson E. Skin hygiene and infection prevention: more of the same or different approaches? Clin Infect Dis 1999;29:1287-1294.

2. Simmons B, Bryant J, Neiman K, Spencer L, Arheart K. The role of handwashing in prevention of endemic intensive care unit infections. Infect Control Hosp Epidemiol 1990;11:589-594.

3. Webster J, Faoagali JL, Cartwright D. Elimination of methicillin-resistant Staphylococcus aureus from a neonatal intensive care unit after hand washing with triclosan. J Paediatr Child Health 1994;30:59-64.

4. Zafar AB, Butler RC, Reese DJ, Gaydos LA, Mennonna PA. Use of $0.3 \%$ triclosan (Bacti-Stat ${ }^{\star}$ ) to eradicate an outbreak of methicillin-resistant Staphylococcus aureus in a neonatal nursery. Am J Infect Control 1995;23:200-208.

5. Casewell M, Phillips I. Hands as route of transmission for Klebsiella species. BMJ 1977;2:1315-1317

6. Maki DG. The use of antiseptics for handwashing by medical personnel.
J Chemother 1989;1:3-11.

7. Massanari RM, Hierholzer WJJ. A crossover comparison of antiseptic soaps on nosocomial infection rates in intensive care units. Am I Infect Control 1984;12:247-248.

8. Doebbeling BN, Stanley GL, Sheetz CT, Pfaller MA, Houston AK, Annis $\mathrm{L}$, et al. Comparative efficacy of alternative hand-washing agents in reducing nosocomial infections in intensive care units. $N$ Engl $J$ Med 1992;327:88-93.

9. Butz AM, Larson E, Fosarelli P, Yolken R. Occurrence of infectious symptoms in children in day care homes. Am J Infect Control 1990;6:347353.

10. Early E, Battle K, Cantwell E, English J, Lavin JE, Larson E. Effect of several interventions on the frequency of handwashing among elementary public school children. Am J Infect Control 1998;26:263-269.

11. Kimel LS. Handwashing education can decrease illness absenteeism. $J$ Sch Nurs 1996;12:14-16.

12. Master D, Hess Longe SH, Dickson H. Scheduled hand washing in an elementary school population. Fam Med 1997;29:336-339.

13. Khan MU. Interruption of shigellosis by handwashing. Trans $R$ Soc Trop Med Hyg 1982;76:164-168.

14. Shahid NS, Greenough WB, Samadi AR, Huq MI, Rahman N. Hand washing with soap reduces diarrhoea and spread of bacterial pathogens in a Bangladesh village. J Diarrhoeal Dis Res 1996;14:85-89.

15. Stanton BF, Clemens ID. An educational intervention for altering watersanitation behaviors to reduce childhood diarrhea in urban Bangladesh. Am J Epidemiol 1987;125:292-301.

16. Jarvis WR. Handwashing-the Semmelweis lesson forgotten? Lancet 1994:344:1311-1312.

17. Albert RK, Condie F. Hand-washing patterns in medical intensive-care units. N Engl J Med 1981;304:1465-1465.

18. Graham M. Frequency and duration of handwashing in an intensive care unit. Am J Infect Control 1990;18:77-81.

19. Thompson BL, Dwyer DM, Ussery XT, Denman S, Vacek P, Schwartz B. Handwashing and glove use in a long-term care facility. Infect Control Hosp Epidemiol 1997;18:97-103.

20. Pittet D, Mourouga P, Perneger TV, and the members of the Infection Control Program. Compliance with handwashing in a teaching hospital. Ann Intern Med 1999;130:126-130.

21. Larson EL. APIC guideline for handwashing and hand antisepsis in health care settings. Am I Infect Control 1995:23:251-269.

22. Rotter ML. Hand washing and hand disinfection. In: Mayhall CG, ed. Hospital Epidemiology and Infection Control. 2nd ed. Philadelphia, PA: Lippincott, Williams \& Wilkins, 1999:1339-1355.

23. Larson E, Killien M. Factors influencing handwashing behavior of patient care personnel. Am J Infect Control 1982;10:93-99.

24. Dubbert PM, Dolce J, Richter W, Miller M, Chapman S. Increasing ICU staff handwashing: effects of education and group feedback. Infect Control Hosp Epidemiol 1990;11:191-193.

25. Conly JM, Hill S, Ross J, Lertzman J, Louie T. Handwashing practices in an intensive care unit: the effects of an educational program and its relationship to infection rates. Am J Infect Control 1989;17:330-339.

26. Sproat LJ, Inglis TJ. A multicentre survey of hand hygiene practice in intensive care units. J Hosp Infect 1994;26:137-148.

27. Larson E, Kretzer EK. Compliance with handwashing and barrier precautions. J Hosp Infect 1995;30:88-106.

28. Kretzer EK, Larson EL. Behavioral interventions to improve infection control practices. Am J Infect Control 1998;26:245-253.

29. Boyce JM. It is time for action: improving hand hygiene in hospitals. Ann Intern Med 1999;130:153-155.

30. Larson E. Handwashing and skin: physiologic and bacteriologic aspects. Infect Control 1985;6:1423.

31. Larson E, McGeer A, Quraishi ZA, Krenzischek D, Parsons BJ, Holdford $\mathrm{J}$, et al. Effects of an automated sink on handwashing practices and attitudes in high-risk units. Infect Control Hosp Epidemiol 1991;12:422-428.

32. Marcil WM. Handwashing practices among occupational therapy personnel. Am J Occupational Therapy 1993;47:523-528.

33. Khatib M, Jamaleddine G, Abdallah A, Ibrahim Y. Hand washing and use of gloves while managing patients receiving mechanical ventilation in the ICU. Chest 1999;116:172-175.

34. Doebbeling BN, Pfaller MA, Houston AK, Wenzel RP. Removal of nosocomial pathogens from the contaminated glove. Ann Intern Med 1988:109:394-398.

35. Voss A, Widmer AF. No time for handwashing!? Handwashing versus alcoholic rub: can we afford 100\% compliance? Infect Control Hosp Epidemiol 1997;18:205-208.

36. Donowitz L. Handwashing technique in a pediatric intensive care unit. Am J Dis Child 1987;141:683-685.

37. Tibballs J. Teaching hospital medical staff to handwash. Med J Aust 1996;164:395-398.

38. Teare EL, Cookson B, French G, Gould D, Jenner E, McCulloch J, et al. Hand washing-a modest measure with big effects. BMJ 1999;318:686-686. 
39. Teare EL, Cookson B, French GL, Jenner EA, Scott G, Pallett A, et al. UK handwashing initiative. J Hosp Infect 1999;43:1-3.

40. Larson EL, Bryan JL, Adler LM, Blane CB. A multifaceted approach to changing handwashing behavior. Am J Infect Control 1997;25:3-10.

41. Weeks A. Why I don't wash my hands between each patient contact. BMJ 1999,319:518.

42. Harbarth S, Sudre P, Dharan S, Cadenas M, Pittet D. Outbreak of Enterobacter cloacae related to understaffing, overcrowding, and poor hygiene practices. Infect Control Hosp Epidemiol 1999;20:598603.

43. Preston GA, Larson EL, Stamm W. The effect of private isolation rooms on patient care practices, colonization and infection in an intensive care unit. Am J Med 1981;70:641-645.

44. Larson E. Compliance with isolation technique. Am J Infect Control 1983;11:221-225.

45. Pettinger A, Nettleman M. Epidemiology of isolation precautions. Infect Control Hosp Epidemiol 1991;12:303-307.

46. Iarson EL, McGinley KJ, Foglia A, Leyden JJ, Boland N, Larson J, et al. Handwashing practices and resistance and density of bacterial hand flora on two pediatric units in Lima, Peru. Am J Infect Control 1992;20:65-72.

47. Zimakoff JD, Pontoppidan B, Larsen SO, Poulsen KB, Stickler DJ. The management of urinary catheters: compliance of practice in Danish hospitals, nursing homes and home care to national guidelines. Scand J Urol Nephrol 1995;29:299-309.

\section{Proposed Tuberculin PPD-S2 as Reference Standard}

\section{Gina Pugliese, RN, MS Martin S. Favero, PhD}

Since 1951, the tuberculin PPD-S1 has been used to standardize commercial PPD reagents and perform special tuberculin surveys. PPD-S1 is now in short supply, and a new standard (PPD-S2) has been manufactured. To determine if PPD-S2 is equivalent and can replace PPD-S1, Villarino and coinvestigators from the CDC; the FDA; Seattle-King County Health Department, University of California, San Diego; University of Arizona, Tucson; Emory University, Atlanta, Georgia; Marion County Health Department, Indianapolis, Indiana; and
Denver Public Health Department, Denver, Colorado, conducted a doubleblind clinical trial. Between May 14 and October 28, 1997, 69 subjects with a history of culture-proven TB (TB patients) and 1,189 subjects with a very low risk for $\mathrm{TB}$ infection were enrolled, received four skin tests (with PPD-S1, PPD-S2, and one each of the commercially available PPDs), and had reactions measured by two trained observers. Among the TB patients, there was statistically indistinguishable immunogenicity (mean reaction size \pm standard deviation): $15.6 \pm 6.6 \mathrm{~mm}$ for PPD-S1 and $14.8 \pm 5.6 \mathrm{~mm}$ for PPD-S2. Among low-risk subjects, the tests had equally high specificities (PPD-S1, 98.7\%; PPD-S2, 98.5\%), using a 10-mm cutoff. The number of discordant (negative vs positive) interpretations for PPD-S2, assuming that low-risk subjects who had $a \geqslant 10 \mathrm{~mm}$ reaction to PPD-S1 were truly infected, was low $(0.5 \%)$ and indistinguishable from the rate of discordant interpretations of the same test when read by two different observers $(0.8 \%)$.

The study results indicate that PPD$\mathrm{S} 2$ is qualified to be used as the new US reference standard for PPD tuberculin.

FROM: Villarino ME, Brennan MJ Nolan CM, Catanzaro A, Lundergan LL, Bock NN, et al. Comparison testing of current (PPD-S1) and proposed (PPD-S2) reference tuberculin standards. Am J Respir Crit Care Med 2000;161 (4 part 1):1167-1171. 